\title{
TRANSFORMASI KOMUNIKASI NON VERBAL PAYAS AGUNG BADUNG PADA UPACARA PERKAWINAN BAGI UMAT HINDU DI KOTA DENPASAR
}

\author{
Tjokorda Istri Bintang Kencana Dewi $\stackrel{\text { a,1 }}{\underline{1}}$ \\ I Wayan Wastawa a \\ I Dewa Ketut Wisnawa a
}

a Universitas Hindu Negeri I Gusti Bagus Sugriwa Denpasar

1 Corresponding Author, email: bintangkencanadewi@gmail.com (Dewi)

\section{ARTICLE INFO}

\section{Article history:}

Received: 12-07-2021

Revised: 19-08-2021

Accepted: 19-09-2021

Published: 30-09-2021

\section{Keywords:}

Transformation of

Non-Verbal

Communication of

Payas Agung

Badung, Marriage

Ceremony

\section{ABSTRACT}

The transformation in Balinese bridal make-up and dress, especially regarding the details on the face and head decoration of the bride, is not solely due to the wishes of the bride herself, but because of the demands of the times. The transformation of traditional Balinese bridal make-up and clothing into the form of modified bridal make-up and clothing cannot be separated from the development of the socio-cultural dynamics of the Denpasar community itself. The dynamic itself can be understood as starting from the emergence of a new trend in Balinese life cycle rituals, especially in wedding ceremonies, namely the emergence of pre-wedding culture among young people which began in the 2001s. The implications of the transformation in Balinese bridal make-up and clothing have had various implications for the social life of people all over the world. The changes that occur in society are caused by three main factors, namely; the need for democratization, advances in science and technology and globalization. Implications for social dynamics The development of this kind of globalization will certainly bring about social change. One of the most prominent socio-cultural changes that occurred as a result of the development of this globalization era was the strengthening of the consumptive behavior of the community, including the people of Denpasar. The transformation of values in the field of Balinese make-up and bridal clothing, either at the level of nista, middle or at the level of Payas agung is due to the development of an increasingly modern society. This can not be separated from the existence of a new order in the development of the social system in this country, including the social order of the Denpasar community, which has implications for various aspects of community life, such as in the field of education

\section{PENDAHULUAN}

Terjadinya perubahan gaya busana Payas Agung Badung saat ini disebut gaya busana kekinian yang telah dimiliki oleh para pelaku seni tat arias atau salon pengantin saat ini. Fenomena ini bahkan sudah masuk ke seluruh lapisan masyarakat di Bali khususnya. Bahkan busana Payas Agung tidak hanya di gunakan oleh 
orang Bali yang beragama Hindu saja, namun karena perubahan zaman modern seperti sekarang ini busana Payas Agung banyak digunakan oleh orang non Hindu, bahkan Payas Agung yang seharusnya digunakan pada saat upacara pernikahan, tetapi di jaman modern seperti sekarang di gunakan untuk acara lain seperti pergelaran yang sifatnya kesekian kali atau digunakan sebagai model penyambutan tamu di acara-acara tertentu.

Permasalahannya, bagaimana pakaian Payas agung ini dapat dipertahankan penggunaannya sesuai dengan ruang dan waktu serta dapat dimaknai sebagai busana adat yang dijiwai oleh nilai-nilai agama Hindu? Sesuai dengan pendapat Canny dan Nancy Etcoff, yaitu pakaian dapat merubah citra, sehingga penampilan adalah membuat eksistensi diri sebagai sebuah identitas diri dan kelompok masyarakat. Untuk itu permasalahan inilah yang menarik bagi penulis untuk melihat transformasi atau pergeseran penggunaan Payas agung Badung dalam perspektif komunikasi nonverbal.

Yang menjadi permasalahan dalam penelitian ini adalah sebagai berikut:

1. Bagaimana bentuk Komunikasi Nonverbal Payas agung Badung pada Upacara Perkawinan bagi umat Hindu di Kota Denpasar?

2. Bagaimana perubahan komunikasi Nonverbal Payas Agung Badung pada Upacara Perkawinan bagi umat Hindu di Kota Denpasar?

3. Apa Implikasi Transformasi Komunikasi Nonverbal Payas Agung Badung pada Upacara Perkawinan bagi umat Hindu di Kota Denpasar?

Kajian Pustaka adalah kajian terhadap penelitian mutahir sebelumnya yang tentu saja relevan dengan penelitian yang dilakukan saat ini Pada kajian pustaka, akan dikemukakan teori penelitian, dan publikasi yang berhubungan dengan transformasi komunikasi non verbal payas agung Badung pada upacara perkawinan bagi umat Hindu di Kota Denpasar untuk dijadikan landasan dalam pembahasan penelitian ini. Menurut Ida Bagus Dharmika (1987/1988) dalam bukunya berjudul "Wujud Pakaian Berkabung" dijelaskan mengenai: susunan pakaian berkabung; cara berpakaian; warna pakaian berkabung. Cara berpakaian dijelaskan, bahwa wastra atau kamben (kain), iyalah kain yang digunakan untuk menutupi badan bagian bawah supaya kelihatan sopan dan berwibawa. Berdasarkan analisa Ida bagus Dharmika di atas, maka karya tulis tersebut juga dapat mendukung penelitian tentang pakaian khususnya Payas agung dalam hal tata cara penggunaan destar, dan wastra bagi kaum peria serta tata cara penggunaan sanggul bagi kaum perempuan Bali.

Penelitian selanjutnya yang dilakukan oleh Tim Peneliti (2016) berjudul "Wastra di Kabupaten Gianyar Bali sebagai Representasi Pusaka Budaya Yang Relgius Mistik". Hasil penelitian mengenai wastra menunjukkan bahwa penggunaan wastra di kabupaten Gianyar berdasarkan tinjauan sejarah sudah ada pada teks tertulis, baik dalam prasasti tinggalan raja Bali Kuno, teks tradisional Jawa Kuno, teks lisan, purana dan dalam tinggalan arkeologi. Penelitian ini dapat memberikan landasan akademis yang lebih menarik dalam analisis penelitian mengenai komunikasi nonverbal Payas Agung Badung di Kota Denpasar.

Penelitian tentang sangat di utamakan penanaman nilai-nilai budaya lewat tata rias pengantin juga dilakukan oleh Ida Bagus Dharmika, dkk (1988) dalam bukunya yang berjudul "Arti Simbol dan Fungsi Tata Rias Pengantin dalam menanamkan nilai-nilai Budaya Luhur Provinsi Bali". Buku ini samasama membahas tentang busana pakaian adat Bali, perbedaan dalam buku ini lebih banyak menjelaskan tentang busana berkabung (berduka). 
Kemudian penelitian yang dilakukan oleh Ni Nyoman Sariyani (2019) dalam jurnal yang berjudul "Pakaian Adat ke Pura Generasi Remaja Hindu di Desa Sari Mekar (Perspektif Sosial, Budaya Dan Religius)". Persamaan isi jurnal dengan penelitian ini sama-sama membahas pakaian perempuan yang menggunakan kamen dengan lipatan kanan dan sama-sama menggunakan perhiasan baik itu gelang, kalung, dan subeng.

Selanjutnya penelitian yang dilakukan oleh I Ketut Darsana (2007) dalam jurnalnya yang berjudul "Tata Rias Busana Adat Bali Aga Desa Tenganan Pagringsingan Dan Desa Asak Karangasem" Bali. Dalam jurnal penelitian ini memperkenalkan ragam busana pengantin adat Bali, sebagai salah satu aspek budaya yang sangat esensial dalam kehidupan manusia untuk dapat menunjukkan jati dirinya umat Hindu Sedaharma.

Sedangkan teori-teori yang dipakai sebagai acuan dalam penelitian ini yaitu: teori tanda nonverbal, teori transformasi budaya, dan teori semiotika fashion

\section{METODE PENELITIAN}

Pada Penelitian ini penulis melakukan penelitian dengan metode deskriptif kualitatif. Penelitian deskriptif memiliki tujuan untuk menggambarkan secara sitematik dan akurat fakta dan karakteristik mengenai populasi atau mengenai bidang tertentu (Sugiono, 2011:199). Lokasi penelitian ini adalah di kota Denpasar Bali. Instrument penelitian ini menggunakan panduan wawancara secara tidak terstruktur agar peneliti mempunyai peluang kebebasan mengoleksi data kepada informan. Dalam hal ini peneliti sebagai kunci informasi atau instrument kunci yang dilengkapi dengan panduan wawancara. Penentuan informan dalam penelitian ini menggunakan metode purposive sampling. Informan yang dimaksud adalah mereka yang sebagai praktisi di bidang pakaian adat Bali, akademisi, dan masyarakat pengguna pakaian adat Bali di Kota Denpasar.

Sumber data yang di peroleh penelitian berasal dari data primer dan data sekunder. teknik pengumpulan data yang dipilih adalah : observasi, wawancara, studi dokumen dan studi kepustakaan. Sedangkan pengolahan data menggunakan teknik analisis deskriptif dan teknik analisis interpretatif. Teknik analisis deskriptif adalah teknik analisis data dengan cara menyusun secara sistematis (Sugiyono, 2007: 147). Sedangkan teknik analisis interpretatif adalah suatu cara pemberian kesan, pendapat, tafsiran atau pandangan teoritis terhadap sesuatu (Fathoni, 2006:34). Dalam penelitian kualitatif setelah data didapatkan berupa tulisan baik dari catatan ataupun rekaman yang sudah direduksi, kemudian dijadikan dalam bentuk deskripsi serta selanjutnya ditarik kesimpulan.

\section{HASIL DAN PEMBAHASAN}

Bentuk Komunikasi Non Verbal Payas Agung Badung pada Upacara Perkawinan bagi Umat Hindu di Kota Denpasar

Busana merupakan salah satu manifestasi budaya. Busana menggambarkan sebuah ekspresi kebudayaan yang pembuatannya tidak semata-mata didorong oleh kebutuhan bilogis, untuk melindungi tubuh pemakainnya dari teriknya matahari dan dinginnya udara, tetapi secara emosional dan sosial banyak di dorong oleh aspirasi estetis sesuai dengan nilai budaya yang menlandasinya (Dinas Kebudayaan Provinsi Bali 2005:1)

Pada masyarakat Bali secara umum, jenis dan busana adat yang digunakan oleh kalangan tertentu sering dikaitkan dengan jenis upacara yang akan dilaksanakan. Misalnya menek bajang (akil balig), busana yang digunakan tentu akan berbeda dengan jenis upacara potong gigi, atau upacara perkawinan dan begitu seterusnya. 
Gambar 1.

Pakem Payas Agung Badung

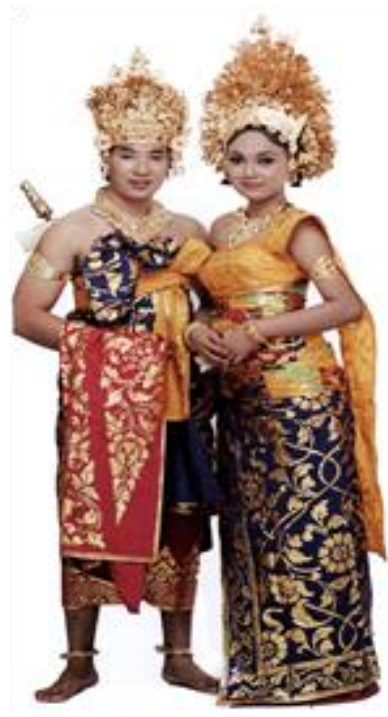

Sumber:

Dr. Dra. A.A. Ayu Ketut Agung, M.M. (2020)

Namun, zaman sekarang penggunaan jenis

Berdasarkan struktur inti, busana pengantin Bali secara umum dapat dibedakan menjadi dua kategori, yakni busana pengantin lanang dan busana pengantin istri. Busana pengantin lanang merupakan pakaian kaum pria yang dipakai pada saat melangsungkan upacara perkawinan dengan unsur-unsur sebagai berikut, udeng (destar), kampuh (saput) dan wastra. Udeng (destar) adalah ikat kepala yang terbuat dari bahan dasar kain yang dilipat dalam bentuk segitiga. Sedangkan busana pengantin istri umumnya terdiri atas tapih (sinjang). Wastra, pepetet (sabuk/stagen), selendang, subeng, sanggul (pusungan), bunga dan cucuk.

Menurut Dinas Kebudayaan Provinsi Bali (2005:3), busana adat Bali dapat digolongkan ke dalam tiga tingkatan, yakni Payas nista (sederhana), Payas madya (menengah) dan Payas agung (tingkat utama).

Payas agung, juga dapat dikategorisasi menjadi tiga kategori, yakni Payas agung nistaning utama, madyaning utama, dan utamaning utama. Tata rias pada kategori terakir di Kota Denpasar disebut Payas agung pengangge Dewi, yakni rias utama yang dikenakan para dewi legendaris di kahyangan. busana ini sangat fleksibel, dalam arti siapapun boleh menggunakannya asal secara ekonomi mereka mampu membeli atau menyewa

Demikian pula dalam lambang-lambang, secara tersendiri tidak dapat membuka dan membeberkan dengan lengkap konsepsi asasi dari kebudayaan suatu masyarakat. Tata rias pengantin daerah Bali menurut klasifikasinya dapat digolongkan ke dalam golongan klasik tradisional, karena di daerah ini masih dijumpai pelestarian tata rias pengantin raja-raja. Hal inilah salah satu yang memungkinkan timbulnya istilah pakaian pengantin (nista, madya, utama). Baik dilihat dari bentuk, bahan dan pembuatannya serta cara menggunakannya pada umumnya memperlihatkan mutu yang sangat tinggi.

Ada yang menarik di sini adalah tata rias muka (untuk pengantin wanita) mempunyai kesamaan antara nista, madya dan utama masing-masing memakai bedak (pupur), semi (anak rambut), serinatha (hiasan dahi) dan alisalis. Fungsi dari serinatha tersebut adalah untuk menyelaraskan bentuk dahi sehingga kelihatan lebih anggun, menarik, cantik bagi pemakainya. Arti lambang yang terkandung di dalamnya sama 
dengan arti lambang dari semi, menandakan seseorang telah dewasa, baik fisik maupun rohani, berani melepaskan diri dari orang tua, mempunyai hak dan kewajiban baru.

Struktur dan perlengkapan Payas Agung Badung pada pengantin wanita dapat diklasifikasi sebagai berikut : bunga kap, bunga sandat emas, bancangan, petitis, puspa lembo, bunga sasak emas, tajug, subeng cerorot,badong, gelang kana, dan pending. Sedangkan pengantin pria terdiri dari : destar atau udeng, subeng, keris, badong, gelang kana, umpal, gelang naga satru, dan kampuh atau saput.

\section{Perubahan Komunikasi Nonverbal pada} Payas Agung Badung pada Upacara Perkawinan Bagi Umat Hindu di Kota Denpasar

Terjadinya transformasi dalam tata rias dan busana pengantin Bali, khususnya menyangkut detail pada hiasan bagian muka dan kepala pengantin wanita, tidak semata-mata disebabkan karena keinginan dari mempelai itu sendiri, melainkan Karena tuntutan perkembangan jaman. Perubahan yang terjadi dari satu bentuk hiasan ke bentuk hiasan berikutnya, bukanlah perkembangan dari suatu bentuk yang sederhana menuju bentuk yang lebih kompleks dan terjadinya secara tiba-tiba (revolusi).

Pesatnya perkembangan jaman membuat bentuk tata rias dan busana pengantin Payas nista pun mengalami tranformasi, ke bentuk yang lebih modis, tren, dan lebih fashionable. Tranformasi yang terjadi semacam ini tidak semata-mata mengandung makna perubahan bentuk tata rias dari yang tradisional, menuju ke bentuk yang modern, akan tetapi juga mengandung makna penggeseran, pemarjinalan, bahkan pelenyapan nilai-nilai tradisional yang disebut dengan istilah detradisionalisasi.

Dampak menggunakan payas agung atau tidak dalam upacara pernikahan itu sendiri tidak ada pengaruhnya dalam keadaan rumah tangga. Hal ini sesuai dengan hasil wawancara penulis dengan salah datu Dosen Seni Budaya di ITB STIKOM Bali Yaitu Ni Putu Setyarini, S.Sn.,M.Sn, terkait dengan dampak dari payas agung dalam upacara perkawinan yaitu sebagai berikut:

"Kalau menurut saya itu sih tidak wajib. Pemakaian payas agung pada saat perkawinan itu disesuaikan dengan keadaan. Sehingga nanti nya tidak menjadi beban bagi si penganten. Menurut pandangan aya tidak ada pengaruhnya juga pada keadaan rumah tangga itu, itu hanya disesuaikan dengan kemampuan penganten saja.

Demikian halnya yang terjadi dalam pemakaian tata rias dan busana pengantin senantiasa mengalami refleksivitas, dari yang kurang praktis menuju ke hal-hal yang lebih praktis, dari hal-hal yang kurang efektif ke halhal yang efektif, dari hal-hal yang kurang efisien ke yang lebih efisien dan begitu seterusnya.

Transformasi dalam bidang tata rias dan busana pengantin Bali, baik pada tingkat Payas nista, madya, atau pada tingkat Payas agung salah satunya disebabkan oleh perkembangan masyarakat yang sudah semakin modern. Hal ini tidak dapat dilepaskan dari adanya tatanan baru dalam perkembangan sosial kemasyarakatan di negeri ini, termasuk tatanan sosial masyarakat Denpasar. Adanya perubahan tatanan dalam kehidupan sosial masyarakat Denpasar.

Terkait dengan kemampuan masyarakat untuk menciptakan berbagai karya baru, terutama dalam bidang tata rias dan busana pengantin. Dharmika (1988:140) menegaskan tata rias dan busana pengantin sebagai hasil karya masyarakat Indonesia, termasuk masyarakat Denpasar tidak hanya sekedar untuk menarik perhatian orang dalam proses pelaksanaan upacara pernikahan. Selain itu, pemanfaatan berbagai lambang atau simbol yang digunakan dalam ornamen tata rias dan busana pengantin, khususnya tata rias dan busana 
pengantin Bali dapat dimaknai berbagai pesan moral yang seharusnya dipahami oleh kedua mempelai dalam mengarungi bahtera kehidupan berumah tangga.

Namun, dalam perkembangan masyarakat yang semakin maju dewasa ini, pemakaian tata rias dan busana pengantin, khususnya pengantin Bali, baik pada Payas nista, madya, maupun utama telah mengalami proses modifikasi, sehingga di dalamnya proses transformasi tidak dapat dihindari. Hal ini tidak dapat dilepaskan dari adanya fakta sosial dalam masyarakat, bahwa setiap masyarakat pasti akan mengalami perubahan sosial-budaya, yang disebabkan oleh kreativitas masyarakat dalam melakukan inovasi.

Salah satu tokoh Agama yang merupakan Wakil Rektor I di ITB STIKOM Bali (Dosen Agama Hindu) memberikan pandangan terhadap penggunaan Payas Agung dalam perkawinan Hindu:

"Payas Agung adalah jenis payasan yang digunakan di Bali sejak Jaman kerajaan. Dan otorisasi kerajaan kemudian mempengaruhi standar atau jenis payas yang digunakan. Jadi jenis payasan disesuaikan dengan status social penggunanya. Payas Agung misalnya ditetapkan sebagai busana para bangsawan atau menak dan tidak dibenarkan digunakan oleh masyarakat yang bukan menak. Pengaruhnya dalam sebuah pernikahan tergantung masa atau waktunya. Kalau dulu ya. Sangat berpengaruh' karena kalau bukan menak pasti tidak akan menggunakan payas Agung. Tatapi kalau sekarang dilaksanakan sepertinya baik tukang payas (penata Rias),penganten maupun keluarganya sudah mulai tidak memperhatikan ketentuan-ketentuan masa lalu. Terhadap perkawinan sendiri tidak pernah disebutkan dalam sastra-sastra bahwa pakaian yang harus di pkai adalah payas apa. Jadi jenis payas lebih kepada kebiasaan dan kreasi seniman payas, dan tidak ada hubungannya dengan persyaratan sebuah pernikahan. (Wawancara tokoh Agama pada tinggal 23 Februari 2021).

Jadi dapat disimpulkan bahwa, payas agung saat ini bisa digunakan oleh semua orang termasuk masyarakat non Hindu. Payas Agung juga yang digunakan oleh masyarakat Hindu khususnya dalam upacara perkawinan tidak ada pengaruhnya dalam kehidupan berumah tangga, bahkan dijaman seperti sekrang ini, payas agung banyak digunakan oleh orang yang non Agama Hindu, bahkan digunakan oleh orang asing. Tidak hanya digunakan dalam upacara perkawinan, namun upacara lainnya, seperti potong gigi, bahkan digunakan untuk sesi foto oleh para tamu asing.

Dalam perkembangannya karena tuntutan perkembangan jaman berbagai nilai sombolis yang digunakan dalam tata rias pengantin dibagian kepala dan wajah pengantin wanita, sebagaimana diuraikan diatas ditransformasikan ke dalam bentuk tata rias dan busana pengantin modifikasi.

\section{Implikasi Transformasi Komunikasi Non Verbal Payas Agung Badung pada Upacara Perkawinan Bagi Umat Hindu di Kota Denpasar}

Implikasi yang ditimbulkan dengan adanya transformasi dalam tata rias dan busana pengantin Bali tidak saja berupa implikasi positif tetapi juga implikasi negatif.

Demikian pula, pemakaian cincin kawin pada jari manis teman hidupnya secara tradisional hal itu bermakna kesetiaan, namun dalam perkembangan dunia yang semakin modern dewasa ini, pemakaiain cincin semacam itu dimaknai sebagai simbol status sosial ekonomi. Artinya, semakin mahal atau semakin mewah cincin yang dikenakannya, maka semakin tinggi pula status sosial mereka dalam masyarakat dan begitu seterusnya. 
Dalam perspktif kebudayaan, penciptaan simbol merupakan suatu respons manusia terhadap challenge, yakni situasi alam yang melingkupinya. Hal ini menurut Cassier (dalam Triguna, 2011:7-8) bahwa manusia itu adalah animal symbolicum.

Terjadinya transformasi nilai-nilai dalam tata rias dan busana pengantin Bali, dapat berimplikasi pada semakin berkurangnya perhatian masyarakat Bali, khususnya para generasi muda terhadap nilai-nilai Budaya tradisional yang sebenarnya mempunyai makna yang sangat tinggi.

Pengaruh budaya terhadap kinerja suatu perekonomian masih menjadi suatu asumsi yang mengikat dalam analisis ilmu ekonomi, khususnya dalam analisis ekonomi neoklasik. Hal ini terkait dengan kesulitan ilmu ekonomi untuk memahami peranan budaya itu sendiri.

Dalam konteks modifikasi tata rias dan busana pengantin Bali, yang menjadi kekawatiran sebagian besar masyarakat Bali, terutama yang perduli terhadap eksistensi kebudayaan Bali adalah dikaburkannya maknamakna simbolis dan filosofi yang ada pada detaildetail tata rias dan pengantin Bali, yang sesungguhnya punya arti penting bagi kehidupan kedua mempelai.

Dalam kaitan perubahan social budaya dan ekonomi, Pendidikan sebagai bagian dari social budaya turut berpengaruh pada perubahan social budaya dan ekonomi masyarakat. Dengan adanya peranan social budaya yang baik akan turut meningkatkan Pendidikan demikian pula sebaliknya Pendidikan yang baik melalui pembelajaran akan turut menanamkan nilainilai social dan budaya yang berisi aturan-aturan sosial, kewajiban sosial, interaksi sesame manusia dan lingkungan sekitar.

\section{SIMPULAN}

Berdasarkan uraian pembahasan diatas, maka dapat disimpulkan adalah sebagai berikut.
1. Bentuk Komunikasi non verbal payas agung Badung di Kota Denpasar, yakni busana merupakan salah satu manifestasi budaya. Cara berpikir pragmatisme yang berkembang pada masyarakat Bali pada umumnya dan masyarakat Denpasar khususnya merupakan salah satu faktor penyebab modifikasi tatrias dan busana pengantin Bali, yang selama ini dikenal dengan istilah payas agung, payas madya, dan payas nista telah dimodifikasi. Dapat dikatakan bahwa penggunan tata rias dan busana pengantin hasil modifikasi dapat memberikan nilai-nilai yang bersifat praktis, pragmatis, efektif, dan efisien bagi para pemakainya. Kuatnya kuasa simbol yang dimainkan oleh kaum kapitalis untuk mengembangkan modalnya, membuat kaum kapitalis dengan mudah dapat menggiring hasrat masyarakat untuk terjebak pada pemaknaan barang atau jasa dari segi simbolik. Artinya, bahwa kuatnya hasrat masyarakat untuk mengkonsumsi barang atau jasa yang bernilai modern tidak sematamata karena masyarat terjerat pada budaya tontonan melainkan sering pula disertai dengan pemaknaan barang buatan pabrik. Dengan demikian masyarakat membeli, memakai atau mengonsumsi suatu barang atau jasa tidak semata untuk menghabiskan nilai guna (nilai utilitas) akan tetapi dipakai pula untuk mengkomunikasikan identitas sosialnya. Simbol status, dan sekaligus untuk mengidentifikasikan dirinya berbeda dari kelompok masyarakat kebanyakan. Hal ini dapat pula dikatakan sebagai salah satu faktor penyebab terjadinya transformasi dalam tata rias dan busana pengantin Bali. Busana Payas agung Badung adalah busana yang dipergunakan seseorang dalam upacara potong gigi, metatah/mepandes, ngeraja sewala (Menekelih) atau beranjak dewasa yang ditandai dengan suara 
membesar bagi anak laki-laki dan sudah datang bulan,bagi anak perempuan dan upacara wiwaha (pernikahan). Busana ini digunakan dalam tingkatan upacara medudus agung (upacara yang ada dalam tingkatan utama). Payas Agung Badung menunjuk pada penggunaan jenis busana atau pakaian oleh raja-raja Badung zaman dahulu di Kabupaten Badung yang sekarang berlokasi di Kota Denpasar. Dan mengandung filosofi Keagungan pada pengantin Bali, keanggunan pada pengantin wanita, kesakralan dalam upacara perkawinan, serta merupakan ciri khas bagi umat Hindu dalam melangsungkan perkawinan.

2. Perubahan komunikasi nonverbal pada payas agung Badung di kota Denpasar pada Pengantin wanita yaitu pada petitisnya yang dibuat modern yang menyerupai subeng dan seminya yang dibuat menyatu pada petites serta dilengkapi dengan bunga sasak pada petites tersebut, serta terletak pada aksesoris simping dan anting dan cincin Kristal yang modern. Untuk selendang dan kamennya masih menggunakan pakem yang terdahulu, sedangkan pada pengantin pria letak perbedaannya menggunakan simping dan bros Kristal yang modern. Sedangkan perubahan Payas Agung Badung pada pengantin Pria yaitu dari kepala menggunakan gelung sedangkan pada zaman dahulu hanya menggunakan destar, kemudian dari segi wajah tampak menggunakan make up lengkap seperti perempuan, Baju yang dilengkapi dengan ukiran di bagian leher dan tangan yang menggunakan baju berjenis safari lengan panjang. Susunan kain pengantin pria menggunakan tapih prada dengan kancut yang tidak runcing dan di genggam oleh tangan pengantin, serta menggunakan kain tenunan yang bernama songket. pada bagian pinggang dililitkan selendang prada. Payas agung pengantin pria dilengkapi dengan aksesori keris kecil sebagai seselet (hiasan pinggang), kemudian di bagian leher dan dada dilengkapi dengan aksesori bross alpaka lengkap dengan subeng alpaka. Pada kaki pengantin pria menggunakan sandal yang menutupi jari kaki yaitu sandal selop khusus laki-laki.

3. Implikasi yang di hasilkan dalam segi ekonomi penyebabnya adalah kebutuhan akan demokratisasi, kemajuan ilmu pengetahuan dan teknologi serta globalisasi, dengan naiknya semua kebutuhan hidup maka apapun akan dilakukan si pemasar atau salon agar mereka memperoleh hasil yang fantastis,serta masuknya kebudayaan asing menyebabkan makin cemerlang si pemasar dalam mengembangkan inovasiinovasi baru untuk menyajikan riasan yang bergaya nyenrtik atau bergaya internasional, meskipun si pemasar tidak memahami apa makna tau symbol dari riasannya menurut mereka tidaklah penting asalkan riasannya terkenal dan banyak yang meminta untuk di riasnya. Dampaknya kurangnya Pemahaman dan pengertian bagi masyarakat Hindu dalam memahami filosofi dalam payas agung pada perkawinan Hindu serta mempengaruhi kesakralan dari riasan pengantin tersebut.

\section{SARAN}

Terkait dengan hasil penelitian, maka ada beberapa saran-saran yang dapat disampaikan yakni sebagai berikut:

1. Kepada para praktisi tata rias dan busana pengantin Bali, khususnya para pemilik salon disarankan agar dalam melakukan modifikasi tata rias dan busana pengantin Bali tidak mentransformasikan secara total nilai-nilai yang ada pada tata rias dan busana pengantin Bali tradisional. 
2. Para pengguna jasa layanan tata rias dan busana pengantin Bali, agar tidak terlalu terjebak pada budaya konsumerisme yang lebih mengutamakan nilai pragmatismenya dibandingkan dengan nilai simbolis dan filosofisnya.

3. Kepada pemerintah Kota Denpasar, khususnya Dinas Kebudayaan disarankan agar hasil penelitian ini dijadikan acuan untuk mengambil kebijakan terkait dengan upaya pelestarian Kebudayaan Bali.

4. Kepada peneliti yang lain yang tertarik dengan objek garapan mengenai transformasi tata rias dan busana pengantin Bali disarankan agar mengkaji persoalan ini dengan melihat sisi-sisi lainnya yang mungkin belum sempat diungkapkan dalam penelitian ini. Dengan demikian diharapkan pengkajian terhadap nilai-nilai tata rias dan busana pengantin Bali dapat dilakukan secara holistik dan komprehensif.

5. Kepada masyarakat Bali secara umum, khususnya yang beragama Hindu disarankan agar dalam memilih tata rias dan busana pengantin tidak terlalu mudah terjebak dalam budaya global. Hal ini selain dapat mengikis keberadaan nilai-nilai budaya local juga mendistorsi nilai-nilai agama Hindu.

6. Kepada seluruh tokoh masyarakat Bali, para agamawan, budayawan, dan juga para akademisi disarankan agar senantiasa mengupayakan jalan bagi tersedianya ruang dan waktu melakukan sosialisasi dan transmisi nilai-nilai budaya Bali, khususnya dalam hal tata rias dan busana adat Bali.

\section{DAFTAR PUSTAKA}

Agung, Anak Agung Ayu Ketut, 2015. Transformasi Nilai-Nilai Tata Rias dan Busana Adat Bali Dalam Upacara Perkawinan di Kota Denpasar. Disertasi, untuk mencapai Gelar Doktor (S-3) Ilmu
Agama dan Kebudayaan Pascasarjana, Universitas Hindu Indonesia, Denpasar.

Anak Agung Ayu Ketut Agung. 2004. Busana Adat Bali, :Pustaka Bali Post

Atep Adya Barata. 2003. Dasar-Dasar Pelayanan

Prima. Jakarta :PT Elex Media Komputindo Kelompok Gramedia.

Atmaja, 2010. Ajeg Bali Gerakan, Identitas Kultural, dan Globalisasi. Yogyakarta: LkiS

Bachtiar, Harsja, W. 1981. Kreativitas Usaha Memelihara Kehidupan Budaya dalam Analitis Kebudayaan No.2 Tahun I. Jakarta: Departemen Pendidikan dan Kebudayaan

Bali Post, 1997. Busana Adat Bali. Denpasar: Pustaka Bali Post

Casson, Mark. 1993. "Cultural Determinants of

Economic Performance." Journal of Comparative Economics. Vol. 17. pp. 418. 442.

Danesi, Marcel. 2011. Pesan, Tanda, dan Makna. Buku Teks Dasar Mengenai Semiotika dan Teori Komunikasi. Yogyakarta : Jalasutra.

Dharmika, Ida Bagus. 1987/1988. Wujud Pakaian Adat Berkabung. Institut Hindu Dharma Denpasar : Majelis Pembina Lembaga Adat Daerah Tingkat I Bali.

Mas, A.A. Gede Raka. 2013 Perkawinan yang Ideal (Menurut Perspektif Hindu) Surabaya: Paramita

Darsana. I Ketut 2007 (Tata Busana Adat Bali Aga Desa Tenganan Pagringsingan Dan Desa Asak Karangasem)

Ernita Dewi, Transformasi Sosial dan Nilai Agama, Jurnal Substantia, Vol. 14, No. 1, April 2012.113-114.

Fakih Mansour, 2004. Bebas dari Neoliberalisme. Yogyakarta: Inist 
Giddens, Antony, 2005. KonsekuensiKonsekuensi Modernitas (Nurhadi, trj.) Yogyakarta: Kreasi Wacana.

Hakam, A.K. (2007). Bunga Rampai Pendidikan Nilai. Bandung: Universitas Pendidikan Indonesia

Hoed, Benny H. 2014. Semiotik dan Dinamika Sosial Budaya. Depok: Komunitas Bambu.

Ibrahim, Idi Subandy. 2007. Budaya Populer Sebagai Komunikasi Dinamika Popscape dan Mediascape di Indonesia Kontemporer. Yogyakarta: Jalasutra.

Ida Bagus Anom, Cv.Kayu Mas Agung.2012. Perkawinan Menurut Adat Agama Hindu.

Kaplan, David \& Robert A. Manners. 2002. Teori Budaya. Yogyakarta: Pustaka Pelajar

Kayun, Umar, 1989. Transformasi Budaya Kita. Teks Pidato pengukuhan Guru Besar. Yogyakarta: Universitas Gajah Mada.

Koentjaraningrat. 1980. Sejarah Antropologi I. Jakarta : UI Press

Kuntowijoyo. (2006). Budaya dan Masyarakat (Edisi Paripurna). Yogyakarta: Tiara Wacana.

Lauer, R.H. 1989. Budaya Konsumen (Hasti T., Champion, trj.) Jakarta: Yayasan Obor Indonesia.

Moleong. 2001. Metode Penelitian Kualitatif. Bandung: Raja Rosdakarya.

Morissan. 2014. Teori Komunikasi Individu Hingga Massa. Jakarta : Kencana.

Picard,Michael. 2006. Bali Pariwisata Budaya dan Budaya Pariwisata. Jakarta :Rajagrafindo Persada.

Piliang Yasraf Amir, 2004. Dunia yang Dilipat Tamasya Melampaui Batas kebudayaan. Yogyakarta : Jala Sutra.

Plawasari, 2000. Busana Adat Bali. Denpasar.
Pujileksono, S. (2009). Antropologi (Edisi Revisi). Malang: UMM Press.

Rich, B. 1999. Menggadaikan Bumi Bank Dunia Pemikiran Lingkungan dan Krisis Pembangunan. (AS Burhan Darn dan Benu Hidayat Penerjemah). Jakarta INFID.

Soekanto, Soerjono. 2013. Sosiologi Suatu Pengantar. Jakarta : PT Raja Grafindo Persada.

Stephanie Jill Najon, dkk, Tansformasi Sebagai Strategi Desain, Media Matrasain, vol.8, no.2 (Agustus, 2011), 120.

Sugiyono. 2010. Metodelogi Penelitian pendektan Kuantitatif, Kualitatif dan R\&D Bandung : Alfabeta

Tesis, Ni Putu Atik Jaya Puti, 2018, Analisis Komunikasi Interpersonal Dalam keluarga Hindu Di Desa Blahbatuh, Gianyar Implikasi Terhadap Pembinaan Karakter Anak.

Tim Peneliti. 2016. Wastra di Kabupaten Gianyar Bali Sebagai Representasi Pusaka Budaya Yang Religius Magis. Gianyar : Pemerintah daerah Kabupaten Gianyar Bekerjasama dengan Institut Hindu Dharma Negeri Denpasar.

Triguna, Yudha I.B Gde, 2011a. Strategi Hindu. Jakarta : Pustaka Jurnal Keluarga

Whitley, R. 1984. The Intellectual and Social Organization of the Sciences. Oxford: Clarendon Press.

Wiasti, Ni Made, 2010. Konstruksi kecantikan Tubuh Perempuan Bali yang Berkarier di Kota Denpasar, Provinsi Bali. Disertasi, untuk mencapai gelar Doktor, pada Program Doktor) S-3) Kajian Budaya, Program Pascasarjana, Universitas Udayana, Denpasar.

Yandianto, Kamus Besar Bahasa Indonesia, (Bandung : Percetakan Bandung, 1997), 208.47 